\title{
Acute Myocardial Infarction. One Century of History
}

\author{
Rogério Sarmento-Leite, Ana Maria Krepsky, Carlos A. M. Gottschall \\ Porto Alegre, RS - Brazil
}

Coronary thrombosis has been a known cause of death since the beginning of the $19^{\text {th }}$ century. On the basis of animal experiments, in which 1 coronary artery was ligated, and limited observations on human postmortem examinations, coronary thrombosis was considered a fatal clinical entity. In 1901, the German Krehl reported that coronary thrombosis not always caused sudden death and that it could be complicated by formation of a ventricular aneurysm and myocardial rupture. These observations were confirmed years later by Obrastov, Strazhesko, and Herrick, who reported the clinical characteristics of acute myocardial infarction and established the differential diagnosis with angina pectoris ${ }^{1}$.

As soon as it became evident that one could survive an acute myocardial infarction, attention was drawn to its treatment. In 1912, James Herrick established the importance of rest in postinfarction recovery; rest was the only therapeutic orientation existing at that time, and it was prescribed in an exaggerated way until the beginning of the 1950s. Patients were required to stay bedridden for up to 6 weeks, and were even forbidden to move or to feed themselves during the first week ${ }^{2}$. James Herrick was also responsible for introducing electrocardiography, which was created by Einthoven in 1902, and has been the major diagnostic tool for acute myocardial infarction up until the present time ${ }^{1}$.

In 1923, Wearn reported the first consecutive series of 19 patients with the clinicopathologic diagnosis of infarction. These patients were prescribed absolute rest, hydric restriction, and use of digitalis for pulmonary congestion, and caffeine and camphor for preventing and treating hypotension, syncope, and cardiac conduction blocks. Five years later, Parkinson and Bedford reported their experience with the use of morphine to relieve pain in a series of $100 \mathrm{pa}-$ tients with acute myocardial infarction. Nitrates were con-

Instituto de Cardiologia do Rio Grande do Sul/Fundação Universitária de Cardiologia

Mailing address: Carlos A.M. Gottschall - IC/FUC - Av. Princesa Isabel, 39590620-001 - Porto Alegre, RS - E-mail: pesquisa@cardnet.tche.br

English version by Stela Maris C. e Gandour traindicated, due to the risk of hypotension, and rest was recommended for the longest time possible, as has already been emphasized ${ }^{1}$.

In 1929, Samuel Levine published the first book exclusively dedicated to the topic of treatment of acute myocardial infarction. In the book, the frequency and risk of several arrhythmias were reported as was the importance of their early detection; quinidine was recommended for ventricular tachycardias and adrenaline for cardiac blocks and syncope.

In the 1950s, acute myocardial infarction was already considered the major cause of death in developed countries and a major public health problem. Due to the evident risk of deep venous thrombosis and pulmonary embolism resulting from prolonged rest, and based on the recommendations by Bernard Lown ${ }^{2}$, who allowed patients to leave their beds, sit in a chair, and walk much earlier, the time of recovery was reduced and a more rapid return to daily activities was recommended. Pharmacological management also evolved, and the need for intense fluid replacement and oxygen use was recommended ${ }^{1}$.

\section{Coronary care units}

In the second half of the $20^{\text {th }}$ century, Desmond Julian, in Great Britain, introduced coronary care units. These units accounted for one of the greatest isolated advances in the treatment of infarction, reducing the mortality rate from $30 \%$ to $15 \%$ in the first hours of evolution. They also contributed to a better appreciation of the diagnosis and management of arrhythmias, to the appearance of continuous cardiac monitoring, to the development of cardiopulmonary resuscitation maneuvers and external defibrillators, and to the better training of physicians and nurses. These advances evolved even more with hemodynamic monitoring through the Swan-Ganz catheter and the use of the intra-aortic balloon counterpulsation, contributing to the aggressive management of heart failure and cardiogenic shock.

Mobile intensive care units also appeared, equipped with material and persons trained in detecting and treating fatal arrhythmias, especially ventricular fibrillation. 
Pharmacological intervention and limitation of the size of the infarct - Preservation of left ventricular function became the major predictive factor of prognosis. The size of the infarct was then defined as the major determinant of mortality and morbidity. The use of injectable and oral betablockers not only to treat arrhythmias, but also to limit myocardial damage induced by the ischemic area, arose as a therapeutic possibility ${ }^{3}$. These drugs reduce oxygen consumption by the myocardium and enhance blood redistribution from the epicardium to the myocardium, diminishing the area of infarct and increasing survival. Clinical trials, such as the MIAMI ${ }^{4}$ and the ISIS- $1^{5}$, showed significant reductions in mortality, especially in the first $48 \mathrm{~h}$ of the event, justifying the early use of these drugs. A lower number of ventricular arrhythmias and a reduction in the incidence of reinfarction in the initial phase of infarction were also observed; these effects may be sustained in the long run with the use of oral beta-blockers ${ }^{6}$.

In regard to calcium channel blockers, no clinical trials detected statistically significant differences in the reduction in cardiovascular events and mortality with their use.

Nitrates were tested in different studies, and in some, the results were favorable, as reported by Yusuf in a metaanalysis ${ }^{7}$. However, other major studies, among which we highlight ISIS- $4^{8}$, did not show any benefit in the routine use of nitrates. They are an unquestionable indication only in cases of recurring angina and heart failure associated with acute myocardial infarction.

The use of magnesium, initially received with enthusiasm due to the publication of the results of several studies, especially LIMIT $-2^{9}$, which reported a significant reduction in mortality in the group of patients treated, proved to be of little help according to the published results of ISIS- $4^{8}$.

The angiotensin-converting enzyme inhibitors have been thoroughly studied and their benefits in reducing mortality and events have been very well documented ${ }^{10,11}$. Currently, their mandatory use is a consensus in patients with poor ventricular function, heart failure, or previous infarction without myocardial reperfusion therapy. Their use is also mandatory in the long-term treatment of patients with well-established atherosclerotic disease, as shown in the recently published HOPE study ${ }^{12}$. The concept of metabolic protection of the ischemic myocardium with the polarizing solution of Sodi-Pallares reappeared in the mid-1990s, based on the DIGAMI study ${ }^{13}$. This study showed a 30\% reduction in death by the end of the first year in a group of diabetic patients treated with the infusion of a glucoseinsulin solution and severe control of the glycemic levels. In a pilot study of the general population ${ }^{14}$, the continuous infusion of a glucose-insulin-potassium solution showed a tendency toward reducing events in the group treated, motivating the performance of more clinical trials to assess the real impact of this medical management.

Contemporary studies, such as $4 \mathrm{~S}^{15}$, CARE ${ }^{16}$, and LIPID ${ }^{17}$, have shown that the treatment with lipid-lowering drugs (statins) in patients with a history of infarction is associated with an up to $30 \%$ reduction in the incidence of death, in new nonfatal infarctions, and in the need for myocardial revascularization. The literature still lacks definitive data in regard to their use in an acute episode.

The reperfusion era - In the 1950s and 1960s, Fletcher and Verstraete, even though experimentally, were the pioneers in the use of thrombolytic agents ${ }^{1}$. In the 1970s, Chazov et al ${ }^{18}$ and Rentrop et al ${ }^{19}$ revolutionized cardiology by showing that the intracoronary infusion of streptokinase could dissolve intracoronary thrombi, therefore limiting the infarct's extension and size. This was corroborated by the studies of De Wood et al ${ }^{20}$, according to which $90 \%$ of patients with clinical findings of infarction and alterations in the ST segment had occlusive thrombi in the coronary arteries. The need for an intracoronary injection, however, was the major obstacle to its use. Intravenous infusion, which is easier and faster, proved to be equivalent to the intracoronary infusion ${ }^{21}$.

Due to the fact that thrombolytic agents can be easily and safely used, they became the standard and most used treatment for acute myocardial infarction. Randomized clinical trials involving thousands of patients, showed, in a trustworthy and consistent way, a reduction in mortality rates ${ }^{22}$.

The first randomized clinical trial from 1986, known as GISSI ${ }^{23}$, included more than 11,000 patients and evaluated the efficacy of intravenous streptokinase as compared with placebo. In 21 days of observation, mortality in the treated group was $10.7 \%$ and $13 \%$ in the control group, corresponding to a $19 \%$ reduction in relative risk and representing 1 life spared for every 43 patients treated. Analysis of the subgroups showed a greater benefit for patients treated in the first 3 postinfarction hours (reduction in relative risk $=26 \%$ ) and between the $3^{\text {rd }}$ and $6^{\text {th }}$ hour (reduction in relative risk $=$ $20 \%$ ). In patients treated after the $6^{\text {th }}$ hour, no statistically significant difference occurred.

Isolated use of streptokinase was compared with that of another thrombolytic agent known as rt-PA (recombinant tissue plasminogen activator) in a phase-1 trial, TIMI- ${ }^{24}$. This study, comprising 290 patients, showed that the latter drug provided faster reperfusion, but showed no significant differences in mortality, in hemorrhagic complications, and in ventricular function.

Another major trial with 17,187 patients, ISIS- ${ }^{25}$, confirmed the effects of streptokinase associated with aspirin, showing a 25\% reduction in relative risk with an NNT (number needed for treatment) of 19 . A $12 \%$ reduction in relative risk occurred in those patients treated between the $12^{\text {th }}$ and $24^{\text {th }}$ postinfarction hour.

Alteplase was effectively tested versus placebo in ASSET ${ }^{26}$ in more than 5,000 patients with a $24.5 \%$ reduction in relative risk in 30 days and a $26.3 \%$ reduction in 6 months. However, no reduction was shown in the incidence of reinfarction, angina, or heart failure.

Anistreplase, compared with placebo, was assessed in the AIMS study ${ }^{27}$. Reductions were observed in the risk of death of $47 \%$ in the first 30 days and $42 \%$ in 1 year.

All these results together with the low incidence of 
severe adverse effects made the use of thrombolytic agents unquestionable in the first hours of acute myocardial infarction. In addition to significantly reducing mortality, thrombolytic agents protect against associated morbid events, such as cardiogenic shock and heart failure, in a direct relation to the speed with which they are administered ${ }^{22}$.

In regard to adverse effects, thrombolytic therapy is related to a small and significant increase in the occurrence of cerebral strokes ${ }^{22}$.

Several clinical trials have compared different thrombolytic agents in regard to the degree of reperfusion, myocardial protection, and decrease in mortality. GISSI- $2^{28}$ is a classical study that compared the efficacy of streptokinase with tissue plasminogen activator (alteplase) in the treatment of infarction. No differences between the groups existed in regard to mortality rate, heart failure, and ejection fraction. The incidence of bleeding, however, was higher among those individuals receiving adjunct heparin.

The TEAM-2 trial $^{29}$, carried out in 1991, did not establish higher coronary artery patency and lower reocclusion rates when comparing APSAC versus streptokinase. Alteplase vs. urokinase vs. both was tested in the TAMI-5 trial ${ }^{30}$ and showed that the combination therapy was more efficient in achieving early reperfusion, and this fact did not mean a lower mortality rate. On the other hand, the TAMI-7 trial $^{31}$, which compared 5 different regimens of alteplase administration, showed that accelerated administration (in 90min) was safe and provided higher coronary artery patency and lower reocclusion rates.

The ISIS-3 trial $^{32}$ showed no differences between the 3 types of thrombolytic agents tested (streptokinase, alteplase, and APSAC) in regard to a reduction in in-hospital mortality and that by the end of 6 months. On the other hand, the incidence of cerebral hemorrhagic stroke was higher in the group receiving alteplase. Soon after, results from the GUSTO- 1 trial ${ }^{33}$ were published. GUSTO-1 assessed 4 groups with different thrombolytic strategies: streptokinase with subcutaneous heparin, streptokinase with intravenous heparin, alteplase of accelerated infusion with intravenous heparin, and a combination of streptokinase and alteplase associated with intravenous heparin. Two differences in regard to the previous studies were the administration of alteplase in $1.5 \mathrm{~h}$ (unlike the conventional infusion in $3 \mathrm{~h}$ ) and the use of intravenous heparin. Mortality in 30 days was $7.2 \%, 7.4 \%, 6.3 \%$, and $7.0 \%$ in the respective groups. A $14 \%$ reduction in the risk and absolute benefit of 1 life spared for every 100 patients treated with alteplase were observed as compared with the 2 groups treated with streptokinase. The association of 2 thrombolytic agents and the use of intravenous heparin with streptokinase did not show advantages but increased the risk of bleeding.

The results of the angiographic subgroup of the GUSTO- 1 trial $^{34}$ also favored the use of accelerated alteplase, and coronary artery patency and slow anterograde coronary flow, called TIMI III flow, were higher at $90 \mathrm{~min}$. Therefore, an advantage in the accelerated strategy of alteplase in association with intravenous heparin was observed, and the costs and benefits of the routine use of this drug, approximately 4 times more expensive than streptokinase, were discussed.

New studies continued to test different thrombolytic agents and their strategies of administration. In the TIMI-4 trial $^{35}$, accelerated rt-PA provided coronary artery reperfusion with obtainment of TIMI III flow earlier and a tendency to better evolution and survival when compared with that provided by APSAC or its combination with rt-PA. The INJECT trial ${ }^{36}$ was designed to compare reteplase with streptokinase. The results in the 6,010 randomized patients were similar, showing that both agents are equivalent in reducing events, with no increase in the bleeding rate. Reteplase, in 3 different types of bolus infusion, was compared with alteplase in 3-hour infusion in the RAPID study ${ }^{37}$. In general, reteplase in double-bolus administration resulted in higher and more complete reperfusion than that obtained with the standard dose of alteplase $(85.2 \%$ vs $77.2 \%$ at $90 \mathrm{~min}$, $\mathrm{p}=0.08)$, with a better index of TIMI III flow obtainment $(62.7 \%$ vs $49.0 \%$ at $90 \mathrm{~min}, \mathrm{p}=0.01)$, which determined a higher ejection fraction at hospital discharge (53\% vs $49 \%$, $\mathrm{p}=0.034)$. However, mortality and heart failure by the end of 30 days had similar incidence rates. Once the efficacy of reteplase in double bolus was confirmed, this strategy was compared with that of accelerated alteplase in the RAPID-2 study ${ }^{38}$, and the advantage of the faster obtainment of TIMI III flow found in the previous study was confirmed; this, however, represented no difference in the patient's evolution.

Accelerated administration of alteplase was compared with the double-bolus infusion of this drug in the COBALT study ${ }^{39}$. No equivalence was observed between them, with a mild tendency toward higher mortality and intracranial bleeding in the second group. The GUSTO III trial ${ }^{40}$, on the other hand, showed an equivalence in effects in regard to reteplase and accelerated alteplase, with a similar rate of events for the patients studied.

The beneficial effect of thrombolytic agents depends on the time factor. Even though with a lower impact, evidence exists that thrombolytic agents may be used from 6 to 12 hours after symptom onset in patients with persistent current of injury or extensive infarction. The LATE study ${ }^{41}$ showed a significant reduction in mortality ( $8.9 \%$ vs $12 \%)$ in patients treated between the $6^{\text {th }}$ and the $12^{\text {th }}$ hour with alteplase versus placebo. The EMERAS Collaborative Group ${ }^{42}$ randomized 4,534 patients with evolution time ranging from 6 to 24 hours to receive streptokinase or placebo. No significant reduction in general mortality was observed; however, in the subgroup of 2,080 patients treated between the $7^{\text {th }}$ and the $12^{\text {th }}$ hour, a nonsignificant tendency toward lower mortality occurred (11.9\% vs $13.2 \%$ ).

The reuse of thrombolytic agents, mainly alteplase, due to the lower risk of hypersensitivity and systemic bleeding, which are common findings with the use of streptokinase, was assessed in a substudy of the GUSTO I study ${ }^{43}$. This strategy was used in $46 \%$ of the reocclusions, showing a significant reduction in mortality when compared with 
that of patients treated in a conservative way ( $11 \%$ vs $24 \%$; $\mathrm{p}<0.001)$.

Promptness in instituting the treatment is one of the major objectives in the search for the ideal thrombolytic therapy. One of the ways of reducing this time and increasing the proportion of patients treated in the first hours would be the prehospital administration of the thrombolytic agent. Some studies were carried out in this direction. The greatest study was the EMIP study ${ }^{44}$, which randomized 5,469 patients and showed that prehospital administration of a thrombolytic agent is feasible and safe. The prehospital treatment reduced by 55 minutes the start of thrombolytic therapy as compared with the in-hospital treatment. Nevertheless, few patients underwent the thrombolytic therapy within the first hour of symptom onset. Even though no significant difference occurred in total mortality, cardiac mortality was reduced by $1.5 \%$ by the end of 30 days. Another study, the MITI-2 study ${ }^{45}$ with 360 patients, failed to show benefits in the reduction of the combined outcome of death, cerebral stroke, major bleeding, and infarct size, or in the improvement in ejection fraction, even though this strategy has been shown to be effective in reducing the time of diagnosis of an acute myocardial infarction.

Therefore, the early detection and prompt referral of cases seem of major importance in the prehospital assessment.

As shown in the angiographic substudy of the GUSTO1 trial ${ }^{34}$, the impact on the reduction in mortality due to coronary reperfusion was caused by the obtainment of TIMI III coronary flow, ie, complete anterograde coronary flow. Even though thrombolytic therapy is the most widespread measure used in the treatment of acute myocardial infarction, it has several limitations: contraindications for its use, dubious benefit in subgroups, limitation in the obtainment of coronary artery patency, and a higher incidence of complications. It is known that approximately $20 \%$ of the patients who receive medical care in the first hours of infarction evolution have some kind of absolute contraindication to the use of thrombolytic agents, such as active bleeding, recent surgery, prolonged cardiopulmonary resuscitation maneuver, and recent hemorrhagic or ischemic cerebral strokes ${ }^{22}$.

Patients with a history of previous myocardial revascularization, poor ventricular function, and those in cardiogenic shock, who are usually excluded from most clinical trials, did not have unquestionably confirmed benefits with the use of thrombolytic agents ${ }^{22}$.

Side effects also limit the obtainment of better results. Thrombolytic therapy has been associated with an increase in the number of cerebral strokes, most of which are hemorrhagic, of 3.9 per 1,000 patients treated. This incidence was higher in patients older than 75 years of age, and caused, in most cases, death or sequela ${ }^{22}$. The occurrence of systemic bleeding requiring transfusion was also higher in the group on thrombolytic agents. In addition, in approximately $20 \%$ of patients, the thrombolytic therapy failed to reach complete reperfusion ${ }^{33}$. Even after apparently very successful thrombolysis and adjunct therapy with heparin and acetylsalicylic acid, the risk of recurring ischemia and reinfarc- tion was approximately $20 \%{ }^{22}$. This might have been due to the fact that the culprit lesion remained with residual stenosis and with a still unstable plaque, representing a worse prognosis and higher cost, as was well demonstrated in the TAMI study ${ }^{46}$ in which reocclusion followed by thrombolysis had a higher rate of morbidity and mortality.

Reperfusion with a catheter-The impossibility and limitations of the use of thrombolytic agents in myocardial reperfusion forced percutaneous transluminal coronary angioplasty to be an alternative treatment.

Percutaneous transluminal coronary angioplasty was used in humans for the first time by Andreas Gruentzig in 1977, and since than this procedure has been increasingly used for the treatment of ischemic heart disease. In 1982, Hartzler et al used primary angioplasty in the treatment of acute myocardial infarction. In the 1990s, this procedure was widely used, and it was accompanied by a lower recurrence of ischemia, a lower incidence of reocclusion due to a new thrombotic event in the culprit artery, and, above all, a lower incidence of restenosis.

In the 1980s, these concepts were initially launched in the medical literature in the observational studies by DeWood on total occlusion of the coronary arteries by a thrombus in the first hours of infarction evolution ${ }^{20}$. Other shorter and encouraging pilot studies also published in the 1980s contributed as well, and they associated primary angioplasty with thrombolytic therapy as combination therapy ${ }^{47}$. Some clinical trials followed ${ }^{48,49}$, showing surprisingly a higher rate of events in the group treated with primary angioplasty as compared with the groups that received only thrombolytic agents, but this was later explained by an inadequate adjunct antithrombotic therapy.

Therefore, the so-called hybrid therapy, which combined thrombolysis with direct angioplasty, did not prove to be very efficient. This did not happen in a series of short studies ${ }^{50,51}$, which assessed only primary angioplasty as a therapeutic measure and obtained positive results. These short studies served as the basis for the major clinical trials, whose objective was to show the superiority of primary angioplasty as compared with thrombolysis in reducing cardiovascular and systemic events.

In recent years, the results of several clinical trials with this objective and involving thousands of patients have been published. A great heterogeneity exists in regard to the type and dosage of thrombolytic agent used, whether or not heparin is used, and the time between diagnosis and treatment onset. The PAMI study ${ }^{52}$ randomized 395 patients with 12 hours of infarction evolution until the beginning of the thrombolytic treatment, which consisted of alteplase or primary angioplasty. This study showed a high index of success with percutaneous transluminal coronary angioplasty (97\%) and a lower immediate incidence of the combined outcome of death and reinfarction (5.1\% vs. $12.0 \%$, $\mathrm{p}=0.02$ ). This incidence was maintained by the end of 6 months $(8.5 \%$ vs. $16.8 \%, \mathrm{p}=0.02)$, in addition to the absence of cerebral bleeding in the group undergoing percutaneous 
transluminal coronary angioplasty. A German study ${ }^{53}$, whose results were published at the same time of those of the PAMI study, randomized 142 patients with 6 hours of infarction evolution and favored the group treated with percutaneous transluminal coronary angioplasty. With high angiographic success $(98 \%)$, the following results were significantly better: higher coronary artery patency ( $91 \%$ vs. $68 \%$ ), improvement in ejection fraction ( $51 \%$ vs. $45 \%)$, less residual stenosis (36\% vs. $76 \%$ ) and recurring ischemia $(9 \%$ vs. $38 \%$ ), and a low probability of a new event ( $0 \%$ vs. $13 \%)$ or of a new need for revascularization ( $4 \%$ vs. $31 \%)$. The Mayo Clinic group ${ }^{54}$, on the other hand, showed no advantage for the patients randomized for primary angioplasty, when compared with those who underwent thrombolytic treatment. Ribeiro et al ${ }^{55}$ had similar findings in a clinical trial with 100 patients.

The GUSTO IIb trial ${ }^{56}$ is perhaps the largest and most representative of all clinical trials, because it used the best thrombolytic strategy with accelerated alteplase, and it randomized patients at 57 different centers in 9 countries. Even though total mortality did not show a statistically significant difference, a significant $33 \%$ reduction occurred in the incidence of the combined outcome of death, reinfarction, and cerebral stroke when percutaneous transluminal coronary angioplasty was compared with thrombolytic therapy $(9.6 \%$ vs. $13.7 \%)$.

Publication of the results of the Primary Angioplasty Registry (PAR) ${ }^{57}$ occurred concomitantly with that of the above-cited studies. PAR gathered information about patients undergoing primary percutaneous transluminal coronary angioplasty, which was performed by very well-trained professionals in 6 centers with extensive experience in this technique, representing the bulk of these procedures performed in the USA. During a period of approximately 2 years, the authors studied 245 patients who had undergone primary percutaneous transluminal coronary angioplasty. Angiographic success was $88 \%$ (residual stenosis lower than 50\%) and obtainment of TIMI III flow occurred in 97\% of the patients, which is, as already known, one of the major determinants of a good prognosis. A low incidence of immediate events was observed, with mortality occurring in $4 \%$ of the patients, reinfarction in $2 \%$, cerebral bleeding in $0.4 \%$, need for reintervention in $5 \%$, and need for revascularization surgery in $9 \%$ of the patients.

Angioplasty versus thrombolysis in the general community -Several large registries were conducted to clarify the relative benefits of primary percutaneous transluminal coronary angioplasty in the general population. Most of them did not identify differences in mortality between the 2 existing strategies. Every et a ${ }^{58}$ showed in a study carried out in several cities near Washington, DC, that minimum differences were observed throughout 1 year of follow-up of the patients undergoing each of the different types of treatment.

Collectively, experience registries are the best reproduction of the so-called real world of primary angioplasty, where physicians can choose the reperfusion strategy according to local conditions and routines. This focuses attention on the question of why some clinical trials show the greater advantage of primary angioplasty as compared with thrombolysis, unlike these registries. Several possible explanations exist as follows: a) the results of the registries are authentic and the differences between the 2 strategies are minimal; b) the prolonged time that elapses from the patient's entrance into the hospital to the installation of the angioplasty balloon ("door-to-balloon" time), which results from the nonroutine use and high complexity of primary percutaneous transluminal coronary angioplasty, may be responsible for the worse results of this alternative in the registries; c) differences between the skills and experiences of the hemodynamics professionals may account for the better results of percutaneous transluminal coronary angioplasty in clinical trials, because this procedure is usually performed in highly skilled and experienced centers. If one considers the first explanation (a) as true, it is mandatory to choose the strategy that is most rapidly available and that can be performed by the best team possible.

"Door-to-balloon" time-Ranging from 40 to 238 minutes according to the study considered ${ }^{59}$, the GUSTO IIb trial ${ }^{56}$ showed very clearly that an important relation exists between the prognosis and the "door-to-balloon" time, with an increase in mortality as time goes by and no procedure is performed. Mortality by the end of 30 days in the patients in whom the first dilation was performed within the first 60min was $1 \%$; in the subgroup dilated between 61 and $90 \mathrm{~min}$, mortality was approximately $4 \%$; in those patients dilated after $90 \mathrm{~min}$, it was $6.4 \%$. This evidence emphasizes that efforts need to be put into reducing this time period to less than $60 \mathrm{~min}$, which requires organization, creation of specific routines inside each institution, and agility, in addition to a rapid selection and diagnosis of patients with a clinical suspicion of infarction. The registry by Every et al ${ }^{58}$ showed an inverse relationship between the number of procedures performed in each institution and the "door-to-balloon" time, meaning more rapid and experienced institutions and professionals.

Even though of difficult clinical detection, the failure of thrombolytic therapy in coronary reperfusion is an indication of the need for immediate referral for angioplasty. This therapy should always be considered when the infarction is extensive, when clinical deterioration of the patient exists, or in case of a previous infarction.

Antiplatelet and anticoagulant therapy - A dramatic reduction in mortality and in the incidence of nonfatal infarctions in patients with unstable angina was obtained with the use of acetylsalicylic acid in doses ranging from 75 to $1,300 \mathrm{mg} /$ day. The extension of these benefits for acute myocardial infarction was very well defined in the ISIS- 2 stu$\mathrm{dy}^{25}$, which concluded that aspirin should be administered as soon as possible at minimum doses of $160 \mathrm{mg}$ in the presence of acute infarction. 
Data from studies on elective angioplasties indicate that aspirin reduces the incidence of acute occlusion after the procedure ${ }^{60}$. Even though this has not been tested in direct percutaneous transluminal coronary angioplasty, extrapolation of these data and those of the ISIS- 2 study 25 also recommends the mandatory use of aspirin in primary angioplasty.

Clinical experience with ticlopidine in patients with acute myocardial infarction is still limited. The Canadian-American study on secondary prevention with ticlopidine ${ }^{61}$ shows a 30\% reduction in the incidence of fatal and nonfatal cardiovascular events when compared with that with the use of aspirin. The benefits of the use of ticlopidine in association with aspirin to replace coumarin anticoagulants after coronary angioplasty with stent implantation are very well established ${ }^{62}$. The advantages obtained in elective procedures can be applied to emergency interventions, such as primary percutaneous transluminal coronary angioplasty.

Clopidogrel was also assessed in analyses of secondary prevention in the CAPRIE study ${ }^{63}$ and proved to be equivalent to aspirin. Several studies ${ }^{64-66}$ compare clopidogrel with ticlopidine, and the only advantage found was the lower incidence of adverse effects with the use of clopidogrel.

With aspirin, ticlopidine, and now clopidogrel already incorporated into current therapeutic strategies, recent clinical trials have shown the importance of more aggressive antiplatelet therapy with platelet glycoprotein IIb/IIIa blockade in the management of acute ischemic syndromes. In the subgroup of patients with acute myocardial infarction treated with primary angioplasty in the EPIC study ${ }^{67}$, an evident benefit was observed in those receiving abciximab when compared with those receiving a placebo. This inspired the RAPPORT clinical trial ${ }^{68}$ in which 483 patients undergoing primary angioplasty were randomized to receive abciximab or placebo. An evident $48 \%$ reduction occurred in the incidence of the combined events death, reinfarction, or need for a new revascularization in the first 30 days. Surprisingly, these benefits did not remain by the end of 6 months, contrary to the results of the EPIC ${ }^{67}$ and EPILOG ${ }^{69}$ studies. In the RAPPORT clinical trial, platelet glycoprotein IIb/IIIa inhibitors also reduced by more than $40 \%$ the need for stents, stressing even more the theory of the need for aggressive antiplatelet therapy in the percutaneous treatment of acute ischemic syndromes.

Two other clinical trials with angiographic and clinical outcomes, the GRAPE pilot study ${ }^{70}$ and the ADMIRAL study, showed that the use of abciximab prior to the direct revascularization procedure still in the emergency room or on the way to the hemodynamics laboratory increases the rate of coronary reperfusion with better and earlier recovery of TIMI III flow in up to $20 \%$ of the patients, when compared with placebo. In addition, the use of abciximab prior to the procedure also promotes improvement in ventricular function. On the other hand, the CADILLAC study randomized 2,082 patients with acute myocardial infarction into 4 groups of treatment as follows: a) stent + placebo; b) stent + abciximab; c) primary percutaneous transluminal coronary angioplasty + placebo; d) primary percutaneous transluminal coronary angioplasty + abciximab. This study showed no immediate or long-term clinical benefit in any of the groups that used platelet glycoprotein IIb/IIIa inhibitors, as compared with those who did not use the drug in this clinical situation. Therefore, unlike what was thought, it seems that the indication for absolute use of platelet glycoprotein $\mathrm{IIb} / \mathrm{III}$ inhibitors is restricted to those cases of complex interventions and unstable angina. Oral platelet glycoprotein IIb/IIIa inhibitors will hardly be tested in this clinical context because of the recent and disappointing results obtained with their use in percutaneous revascularization procedures, which were evidenced in the EXCITE, FROST, and OPUS-TIMI 16 studies.

Anticoagulant agents, especially heparin, have been traditionally used as adjuncts to thrombolytic therapy and primary angioplasty in the acute phase of infarction with the aim of avoiding new thrombotic events, which does not mean they are very advantageous. Mahaffey et al carried out a meta-analysis ${ }^{71}$ of 6 randomized clinical trials with more than 1,735 patients, who had undergone thrombolytic therapy. In-hospital mortality was $5.1 \%$ in those patients receiving heparin versus $5.6 \%$ in the control group; this difference was statistically insignificant, contrary to the incidence of systemic bleeding, which was significantly higher in the group treated with anticoagulant agents. Some clinical trials tested high doses of heparin as an alternative to the use of thrombolytic agents, but found no difference.

The dosage and duration of the treatment with heparin varies according to the type of thrombolytic agent used and whether or not an association exists with platelet glycoprotein IIb/IIIa inhibitors. With streptokinase, for example, according to data from the ISIS- $3^{32}$ and GUSTO 1 trials ${ }^{33}$, no routine use of heparin is required. Therefore, the exact role played by heparin in improving initial reperfusion, preventing reocclusion, and reducing mortality remains uncertain.

Use of stents in acute myocardial infarction - Introduction of stent implantation has been the major isolated change in the era of catheter reperfusion in the last few years.

With a better understanding and development of the combined use of aspirin and ticlopidine in the prophylaxis of thrombotic phenomena, thrombosis of stents has been significantly reduced, and implantation of stents in the acute phase of infarction has become feasible.

Recent clinical trials have shown the potential superiority of stent implantation over conventional angioplasty. The FRESCO study ${ }^{72}$ randomized 150 patients for elective stent placement or conventional angioplasty for the treatment of acute infarction. The study showed no difference in the isolated incidence of death or reinfarction, but a great reduction in angiographic restenosis (17\% vs. $43 \%$ ) and in the need for new revascularization of the infarct-related vessel in up to 6 months (7\% vs. 25\%) was observed. These data are similar to those reported in the GRAMI ${ }^{73}$, ESCO$\mathrm{BAR}^{74}$, and STENT-PAMI ${ }^{77}$ trials. 
The CADILLAC clinical trial, which tested the combination of primary angioplasty, stents, and abciximab as already mentioned, did not favor the group that received platelet glycoprotein IIb/IIIa inhibitors. On the other hand, the 2 groups in which stents were implanted (a - stent + placebo, b-stent + abciximab), independently of the use of abciximab, had a better evolution as compared with the groups undergoing angioplasty (c - percutaneous transluminal coronary angioplasty + placebo, $\mathrm{d}$ - percutaneous transluminal coronary angioplasty + abciximab). A significant reduction occurred in the combined events of death, reinfarction, hospitalization, and need for new revascularization of the target vessel (a- $10.9 \%$ vs b- $10.8 \%$ vs c $-19.3 \%$ vs d $-15.2 \%$; $\mathrm{p}=0.0001$ ), and it was more evident in the 6-month follow-up. The benefit seems to be secondary to a greater stabilization of the infarct-related vessel in the acute phase, with greater immediate luminal gain and lower long-term loss, instead of being due to a more potent inactivation of platelet activity.

Therefore, until new evidence appears, stents certainly do not reduce mortality, but interfere positively in the reduction of restenosis and of new interventions.

Primary angioplasty in special subgroups - Some special subgroups of patients, such as those in cardiogenic shock, those with occlusion of venous grafts, and the elderly, deserve special attention.

The incidence of cardiogenic shock after infarction ranges from $5 \%$ to $15 \%$, and it is the most common cause of death in the in-hospital phase ${ }^{22}$. Measures of support, such as intra-aortic counterpulsation balloon, may promote transient improvement if immediate revascularization is not possible. Even though thrombolytic therapy reduced total mortality in acute myocardial infarction and the incidence of cardiogenic shock, until very recently no large clinical trial existed assessing improvement in survival in this specific situation. In the GISSI trial ${ }^{23}$, mortality in 30 days was $69.9 \%$ for 146 patients treated with streptokinase and $70.1 \%$ for 134 patients treated with placebo.

All these benefits of primary angioplasty have been reported in observational studies and case series, but the real benefit of primary angioplasty was tested only in 2 clinical trials. The SMASH trial ${ }^{75}$ failed to show a benefit, and it was interrupted because of the insufficient number of patients. The randomized clinical trial SHOCK ${ }^{76}$ compared percutaneous transluminal coronary angioplasty or emergency myocardial revascularization and maximum clinical treatment in patients with infarction, who developed cardiogenic shock, excluding the mechanical causes. Even though the expected $20 \%$ reduction in mortality rate was not confirmed, mortality was lower in the group treated invasively, especially when the subgroup of patients under the age of 75 years was analyzed. It seems, therefore, that the real benefit of primary angioplasty in cardiogenic shock is lower than that expected, perhaps because of a defect in the selection of patients referred to the hemodynamics laboratory in smaller studies. However, primary angioplasty is still the best alternative in the treatment of this subgroup of patients, mainly when associated with other methods of life support.

Patients with a history of previous myocardial revascularization and with infarction secondary to occlusion of a venous aorto-coronary graft are known to respond poorly to thrombolytic therapy, with rates of success very inferior to those observed in patients with occlusion of native vessels. Therefore, primary angioplasty has become the therapeutic strategy of choice for these patients in the centers where it is available.

In regard to the elderly, controversies still persist. In the 6-month follow-up of the PAMI trial ${ }^{77}$, advantages were observed in the group that underwent percutaneous transluminal coronary angioplasty. In a substudy of the GUSTO IIb trial ${ }^{78}$, however, this benefit was not shown. Based on this latter large and representative clinical trial, we conclude that the elderly should be treated in a manner similar to that in which the young are treated, ie, choosing the most rapidly available and better performed therapy.

The future of reperfusion through the use of a catheter - The progress in general and interventional cardiology is amazing. It is evident that this area will undergo transformations, and many discoveries are still to come. The better understanding of the pathophysiology of acute ischemic syndromes is associated with new therapeutic perspectives, which go beyond simple obstruction of coronary artery flow. The continuous development and use of platelet glycoprotein IIb/IIIa inhibitors, stent implantation, and the perfect knowledge of dynamic phenomena, such as thrombosis, genetics, inflammation, and possibly infectious agents and plaque stabilizers, will be the central focus of this old, but always renewed discussion. Advantages and benefits will only be consolidated at the moment when the "doorto-balloon" time is reduced and the centers of excellence provide first-line material and keep their professional team trained and skilled.

The possibility of a shorter time of hospitalization with cost reduction has been considered, and it is feasible, indicating that radical changes in the current approach to acute myocardial infarction may occur.

Therefore, other targets of treatment are to be elucidated. High-technology science and evidence-based medicine will undoubtedly answer these questions, bring new knowledge, and certainly raise other questions. 


\section{References}

1. Brauwald E. Evolution of the management of acute myocardial infarction: a 20th century saga. Lancet 1998; 352: 1771-4.

2. Lown, B. The Lost art of healing.: Houghton Mifflin Company ( $1^{\text {st }}$ ed), 1996: 332

3. International Collaborative Group. Reduction of infarct size with early use of timolol in acute myocardial infarction. NEngl J Med 1984; 310 : 9.

4. The MIAMI trial research group. Metoprolol. In: Acute Myocardial Infarction (MIAMI) - A randomized placebo-controlled international trial. Eur Heart J 1985; 6: 199-226

5. ISIS-1 [First International Study of Infarct Survival] Collaborative Group. Randomized trial of intravenous atenolol among 16027 cases of suspected acute myocardial infarction. Lancet 1986; 2: 57-65.

6. Beta-Blocker Heart Attack Trial Research Group. A randomized trial of propanolol in patients with acute myocardial infarction: I. Mortality results. JAMA 1982; 247: 1707-14.

7. Yusuf S, Collins R, MacMahon S, et al. Effect on intravenous nitrates on mortality in acute myocardial infarction: an overview of the randomized trials. Lancet 1988; 1: 1088-92.

8. ISIS-4 (Fourth International Study of Infarct Survival) Collaborative Group. ISIS-4: A randomized factorial trial assessing early oral captopril, oral mononitrate, and intravenous magnesium sulphate in 58.050 patients with suspected acute myocardial infarction. Lancet 1995; 345: 669-85.

9. Woods KL, Fletcher S, Roffe CH, Haidar Y. Intravenous magnesium sulphate in suspected acute myocardial infarction: Results of the second Leicester Intravenous Magnesium Intervention Trial (LIMIT-2). Lancet 1992; 339: 1553-8.

10. The Acute Infarction Ramipril Efficacy (AIRE) study investigators. Effect of ramipril on mortality and morbidity of survivors of acute myocardial infarction with clinical evidence of heart failure. Lancet 1993; 342: 821-8.

11. Swedberg K, Held P, Kjekshus J, et al. Effects of the early administration of enalapril on mortality in patients with acute myocardial infarction. Results of the Cooperative Scandinaviam Enalapril Survival Study II (CONSENSUS II). N Engl J Med 1992; 327: 678-84.

12. The Heart Outcomes Prevention Evaluation (HOPE) Study Investigators. Effects of an angiotensin converting-enzyme inhibitor, ramipril, on cardiovascular events in high-risk population. N Engl J Med 2000; 342: 145-53.

13. Malmerg K, Ryden L, Efendic S, et al. Randomized trial of insulin-glucose infusion followed by subcutaneous insulin treatment in diabetic patients who have had acute myocardial infarction (DIGAMI Study): Effects on mortality at 1 year. J Am Coll Cardiol 1995; 26: 57-65.

14. Díaz R, Paolasso EA, Piegas LS, et al. Metabolic Modulation of Acute Myocardial Infarction: The ECLA Glucose-Insulin-Potassium Pilot Trial. Circulation 1998; 98: 2227-34.

15. Pedersen TR, Kjekshus J, Berg K, et al. Randomized Trial of Cholesterol lowering in 4444 Patients with Coronary Heart Disease: The Scandinavian Simvastatin Survival Study (4S). Lancet 1994; 344: 1383-9.

16. Sacks FM, Pfeffer MA, Move LA, et al. The Effect of Pravastatin on Coronary Events After Myocardial Infarction in Patients with Average Cholesterol Levels. The Cholesterol and Recurrent Events Trial (CARE). N Engl J Med 1996; 335: 1001-9.

17. The Long-Term Intervention with Pravastatin in Ischemic Disease (LIPID) Study Group. Prevention of Cardiovascular Events and Death with Pravastatin in Patients with Coronary Heart Disease and a Broad Range of Initial Cholesterol Levels. N Engl J Med 1998; 339: 1349-57.

18. Chazov EI, Matveea LS, Karsch KR, et al. Intracoronary administration of fibrinolysin in acute myocardial infarction. Terapeuticheskii Arkhiv 1976; 48: 8-18.

19. Rentrop KP, Blanke H, Karsch KR, et al. Acute myocardial infarction: intracoronary application of nitroglycerin and streptokinase. Clin Cardiol 1979; 2: 354-63.

20. De Wood MA, Spires J, Notske R, et al. Prevalence of total coronary occlusion during the early hours of transmural myocardial infarction. N Engl J Med 1980; 303: 897-902.

21. Alderman EL, Jutzy KR, Berte LE, et al. Randomized comparison of intravenous versus intracoronary streptokinase for myocardial infarction. Am J Cardiol 1984; 54: 14-9.

22. Fibrinolytic Therapy Trialists' (FTT) Collaborative Group. Indications for fibrinolytic therapy in suspected acute myocardial infarction: collaborative overview of early mortality and major morbidity results from all randomized trials of more than 1000 patients. Lancet 1994; 343: 311-22.

23. Gruppo Italiano per lo Studio Della Streptochinase Nell' Infarto Miocardico (GISSI). Effectiveness of intravenous thrombolitic therapy in acute myocardial infarction. Lancet 1988; 1: 397-402.

24. Chesbero JH, Knaterud G, Roberts R, et al. Thrombolysis in Myocardial Infarction (TIMI) Trial, phase I: a comparison between intravenous tissue plasminogen activator and intravenous streptokinase. Clinical findings through hospital discharge. Circulation 1987; 76: 142-54.
25. ISIS-2 Collaborative Group. Randomized trial of intravenous streptokinase, oral aspirin, both, or neither among 17187 cases of suspected acute myocardial infarction: ISIS-2. Lancet 1988; II: 349-60.

26. Anglo-Scandinaviam Study of Early Thrombolysis (ASSET). Trial of tissue plasminogen activator for mortality reduction in acute myocardial infarction. Lancet 1988; 2: 525-30.

27. AIMS Trial Study Group. Long-term effects of intravenous anistreplase in acute myocardial infarction: final report of the AIMS study. Lancet 1990; 335: 427-31.

28. Grupo Italiano per lo Studio Della Streptochinase Nell' Infarto Miocardico (GISSI-2): a factorial randomized trial of alteplase versus streptokinase and heparin versus on heparin among 12490 patients with myocardial infarction. Lancet 1990; 336: 65-71.

29. Anderson JL, Sorensen SG, Moreno FL, et al. Multicenter patency trial of intravenous anistreplase compared with streptokinase in acute myocardial infarction. Circulation 1991; 83; 126-40.

30. Califf RM, TopolEJ, Stack RS, et al. Evaluation of combination thrombolytic the rapy and timing of cardiac catheterization in acute myocardial infarction. Results of Thrombolysis and Angioplasty in Myocardial Infarction-phase 5 randomized trial. Circulation 1991; 83: 1543-56.

31. Wall TC, Califf RM, Georges BS, et al. Accelerated plasminogen activator dose regimens for coronary thrombolysis. J Am Coll Cardiol 1992; 19: 482-9.

32. Third International Study of Infarct Survival Collaborative Group. ISIS-3: a randomized trial of streptokinase vs tissue plasminogen activators anistreplase and aspirin plus heparin vs aspirin alone among 41299 cases suspected acute myocardial infarction. Lancet 1992; 339: 753-70.

33. The GUSTO investigators. An international randomized trial comparing four thrombolytic strategies for acute myocardial infarction. The GUSTO trial. NEngl J Med 1993; 329: 673-80.

34. The GUSTO Angiographic Investigators. The effects of tissue plasminogen activator, streptokinase, or both on coronary-artery patency, ventricular function, and survival after acute myocardial infarction. NEngl J Med 1993; 329: 1615-22.

35. Cannon CP, $\mathrm{McCabe} \mathrm{CH}$, Diver DJ, et al. Comparison of front loaded recombinant tissue-type plasminogen activator, anistreplase and combination thrombolytic therapy for acute myocardial infarction: Results on the Thrombolysis in Myocardial (TIMI) 4 trial. J Am Coll Cardiol 1994; 24: 1602-10.

36. International Joint Efficacy Comparison of Thrombolytics. Randomized, doubleblind comparison of reteplase double-bolus administration with streptokinase in acute myocardial infarction (INJECT): trial to investigate equivalence. Lancet 1995; 346: 329-36.

37. Smalling RW, Bode C, Kalbfleisch J, et al. More rapid, complete, and stable coronary Thrombolysis with bolus administration of reteplase compared with alteplase infusion in acute myocardial infarction. Circulation 1995; 91: 2725-32.

38. Bode C, Smalling RW, Berg G, et al. Randomized comparison of coronary thrombolysis achieved with double-bolus reteplase (recombinant plasminogen activator) and front-loaded, accelerated alteplase (recombinant tissue plasminogen activator) in patients with acute myocardial infarction. Circulation 1996; 94 : 891-8.

39. The continuous Infusion versus Double-Bolus Administration of Alteplase (COBALT) Investigators. A comparison of continuous infusion of alteplase with double-bolus administration for acute myocardial infarction. N Engl J Med 1997; 337: 1124-30

40. The Global Use of Strategies to Open Occluded Coronary Arteries (GUSTO III) Investigators. A comparison of reteplase with alteplase for acute myocardial infarction. N Engl J Med 1997; 337: 1118-23.

41. Late Study Group. Late assessment of thrombolytic efficacy (LATE) study with alteplase 6-24 hours after onset of acute myocardial infarction. Lancet 1993; 342: 759-66.

42. EMERAS Collaborative Group. Randomized trial of late thrombolysis in patients with suspected acute myocardial infarction. Lancet 1993; 342: 767-72.

43. Barbash GI, Ohman EM, White HD, et al and the GUSTO Investigators. Rescue thrombolysis for suspected reinfarction following thrombolytic therapy: experience infarction. Lancet 1993; 342: 759-66.

44. The European Myocardial Infarction Project Group. Prehospital thrombolytic therapy in patients with suspected acute myocardial infarction. N Engl J Med 1993; 329: 383-9.

45. Weaver DW, Cerqueira M, Hallstrom AP, et al. Prehospital-initiated vs. hospital-initiated thrombolytic therapy. The myocardial infarction triage and intervention trial. JAMA 1993; 270: 1211-6.

46. Ohman EM, Callif RM, Topol EJ, et al. Consequences of reoclusion after successful reperfusion therapy in acute myocardial infarction. TAMI Study Group. Circulation 1990; 82: 781-91.

47. Topol EJ, Eha JE, Brin KP, et al: Applicability of percutaneous transluminal coro- 
nary angioplasty to patients with recombinant tissue plasminogen activator mediated thrombolysis. Cathet Cardiovasc Diagn 1985; 11: 337-48.

48. Topol EJ, Morris DC, Smalling RW, et al. A randomized trial of immediate versus delayed elective angioplasty after intravenous tissue plasminogen activator in acute myocardial infarction. N Engl J Med 1987; 317: 581-8.

49. The TIMI Study Group: Comparison of invasive and conservative strategies following intravenous tissue plasminogen activator in acute myocardial infarction: Results of the Thrombolysis in Myocardial Infarction (TIMI) II Trial. N Engl J Med 1989; 320: 618-28.

50. Ellis SG, O'Neill WW, Bates ER, et al. Coronary angioplasty as primary therapy for acute myocardial infarction 6 to 48 hours after symptom onset: Report of an initial experience. J Am Coll Cardiol 1989; 13: 1122-6.

51. Brodie BR, Weintraup RA, Stuckey TD, et al. Outcomes of direct coronary angioplasty for acute myocardial infarction in candidates and non-candidates for thrombolytic therapy. Am J Cardiol 1991; 67: 7-12.

52. Grines CL, Browne KF, Marco J, et al. A comparison of immediate angioplasty with thrombolytic therapy for acute myocardial infarction- The Primary Angioplasty in myocardial Infarction Study Group. N Engl J Med 1993; 328: 673-9.

53. Zijlstra F, de Boer MJ, Hoornetje JC, et al. A comparison of immediate coronary angioplasty with intravenous streptokinase in acute myocardial infarction. N Engl J Med 1993; 328: 680-

54. Gibbons RJ, Holmes DR, Reeder GS, et al. Immediate angioplasty compared with the administration of a thrombolytic agent followed by conservative treatment for myocardial infarction. The Mayo Coronary Care Unit and Catheterization Laboratory Groups. N Engl J Med 1993; 328: 685-91.

55. Ribeiro EE, Silva LA, Carneiro R, et al. Randomized trial of direct coronary angioplasty versus intravenous streptokinase in acute myocardial infarction. J Am Coll Cardiol 1993; 22: 376-80.

56. The GUSTO II Investigators: A clinical trial comparing primary coronary angioplasty with tissue plasminogen activator for acute myocardial infarction. NEngl J Med 1997; 336: 1621-8

57. O'Neill WW,Brodie BR, Ivanhoe R, etal.Primary coronary angioplasty for acute myocardial infarction(The Primary Angioplasty Registry). AmJ Cardiol 1994; 73:627-34.

58. Every NR, Parsons LS, Hlatky M, et al, for the Myocardial Infarction Triage and Intervention Investigators. A Comparison of Thrombolytic Therapy with Primary Coronary Angioplasty for Acute Myocardial Infarction. N Engl J Med 1996; 335: 1253-60.

59. Weaver WD, Simes RJ, Betriu A, et al for Primary Coronary Angioplasty vs Thrombolysis Collaboration Group. Comparison of primary angioplasty and intravenous thrombolytic therapy for acute myocardial infarction: A quantitative review. JAMA 1997; 278: 2093-8

60. Schwartz L, Bourassa MG, Lesperance J, et al. Aspirin and dipyridamole in the prevention of restenosis after percutaneous transluminal coronary angioplasty. N Engl J Med 1988; 318: 1714-9.

61. Gent M, Blakely JA, Easton JD, et al. Canadian American Ticlopidine Study (CATS) in thromboembolic stoke. Lancet 1989; 1: 1214-20.

62. Schomig A, Neumann FJ, Kastrati A, et al. A randomized comparison of antiplate- let and anticoagulant therapy after the placement of coronary artery stents. NEngl J Med 1996; 334: 1084-9.

63. CAPRIE Investigators. A randomized, blinded trial of clopidogrel versus aspirin in patients at risk of ischaemic events (CAPRIE). Lancet 1996; : 1329-39.

64. Moussa I, Oetgen M, Roubin G, et al. Effectiveness of clopidogrel and aspirin versus ticlopidine and aspirin in preventing stent thrombosis after coronary stent implantation. Circulation 1999; 99: 2364-6.

65. Berger PB, Bell MR, Rihal CS, et al. Clopidogrel versus ticlopidine after intracoronary stent placement. J Am Coll Cardiol 1999; 34: 1891-4.

66. MullerC, Buttner HJ, Petersen J, Roskmamn H. A randomized comparison of clopidogrel and aspirin versus ticlopidine and aspirin after the placement of coronary artery stents. Circulation 2000; 101: 590-3.

67. The EPIC Investigators. Use of a monoclonal antibody directed against the platelet glycoprotein IIb/IIIa receptor in high-risk coronary angioplasty. N Engl J Med 1994; 330: 956-61

68. Brener SJ, Barr LA, Burcheral JEB, et al on behalf of the ReoPro and Primary PTCA Organization and Randomized Trial (RAPPORT) Investigators. Randomized, placebo-controlled trial of platelet glycoprotein IIb/IIIa blockade with primary angioplasty for acute myocardial infarction. Circulation 1998; 98: 734-41.

69. The EPILOG Investigators. Platelet glycoprotein IIb/IIIa receptor blockade and low-dose heparin during percutaneous coronary revascularization. N Engl J Med 1997; 336: 1689-96.

70. LambertFM, Merkhof VD,ZijlstraF, etal. Abciximab in the treatment of acute myocardial infarction eligible for primary percutaneous transluminal coronary angioplasty: Results of the glycoprotein receptor antagonist patency evaluation (GRAPE) pilot study. J Am Coll Cardiol 1999; 33: 1528-32.

71. Mahaffey KW, Granger CB, Collins R, et al. Overview of randomized trials of intravenous heparin in patients with acute myocardial infarction treated with thrombolytic therapy. Am J Cardiol 1996; 77: 551-6.

72. Antoniucci DA, Santoro GM, Bolognese L, et al. A clinical trial comparing primary stenting of the infarct-related artery with optimal primary angioplasty for acute myocardial infarction. J Am Coll Cardiol 1998; 31: 1234-9.

73. Rodriguez A, Bernardi V, Fernandez M, et al. In-hospital and late results of coronary stent versus conventional balloon angioplasty in acute myocardial infarction (GRAMI trial). Am J Cardiol 1998; 81: 1286-91.

74. Suryapranata H, Van't Hof AWJ, Hoorntje JCA, et al. Randomized comparison of coronary stenting with balloon angioplasty in selected patients with acute myocardial infarction. Circulation 1998; 97: 2502-5.

75. Urban P, Stauffer JC, Bleed D. A randomized evaluation of early revascularization to treat shock complicating acute myocardial infarction. The (Swiss Multicenter Trial of Angioplasty for Shock) SMASH. Eur Heart J 1999; 20: 1030-8.

76. Hochman JS, Sleeper LA, Weeb JG, et al.Early revascularization in acute myocardial infarction complicated by cardiogenic shock. N Engl J Med 1999; 341: 625-34.

77. Stone GW, Grines CL, Browne KE, et al. Predictors of in-hospital and 6-month outcome after acute myocardial infarction in the reperfusion era: The Primary Angioplasty in Myocardial Infarction (PAMI) Trial. J Am Coll Cardiol 1995; 25: 370-7.

78. HolmesDR, WhiteHD,PieperKS, etal.Effectofageonoutcome with primary angioplasty vs. Thrombolysis: The GUSTO Ilb randomized trial. J Am Coll Cardiol 199; 33:412-9.

\section{ERRATA}

Por falha gráfica, a figura da Correlação Clínico-Radiográfica de Arq. Bras Cardiol 2001; 77 (nº 5): 493 foi impressa com erro a correta é:

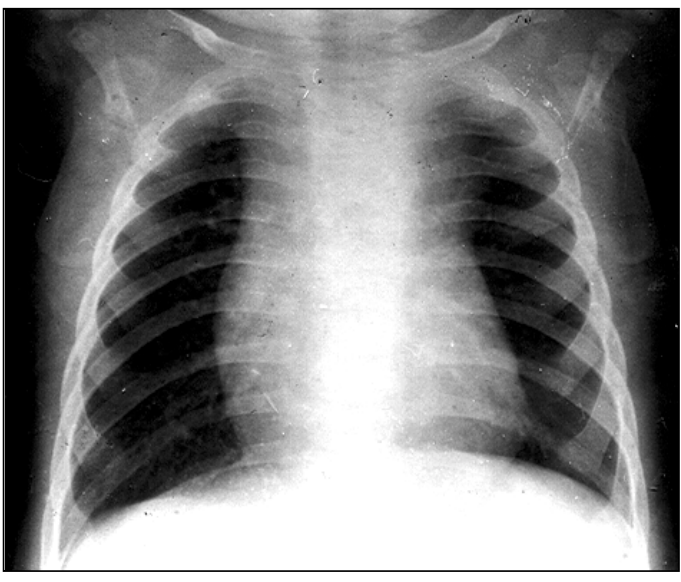

